\title{
Erratum to: Association of Autophagy in the Cell Death Mediated by Dihydrotestosterone in Autoreactive T Cells Independent of Antigenic Stimulation
}

Ting Jia ${ }^{1}$ - Annadurai Anandhan ${ }^{1} \cdot$ Chandirasegaran Massilamany ${ }^{1}$.

Rajkumar A. Rajasekaran ${ }^{1} \cdot$ Rodrigo Franco $^{1} \cdot$ Jay Reddy $^{1}$

Published online: 1 December 2015

(C) Springer Science+Business Media New York 2015

Erratum to: J Neuroimmune Pharmacol (2015)

DOI 10.1007/s11481-015-9633-x

The original version of this article unfortunately contained a mistake. The presentation of Fig. 2a was incorrect. The corrected figure is given below. 
(a) Dextramer staining: flow cytometric plots

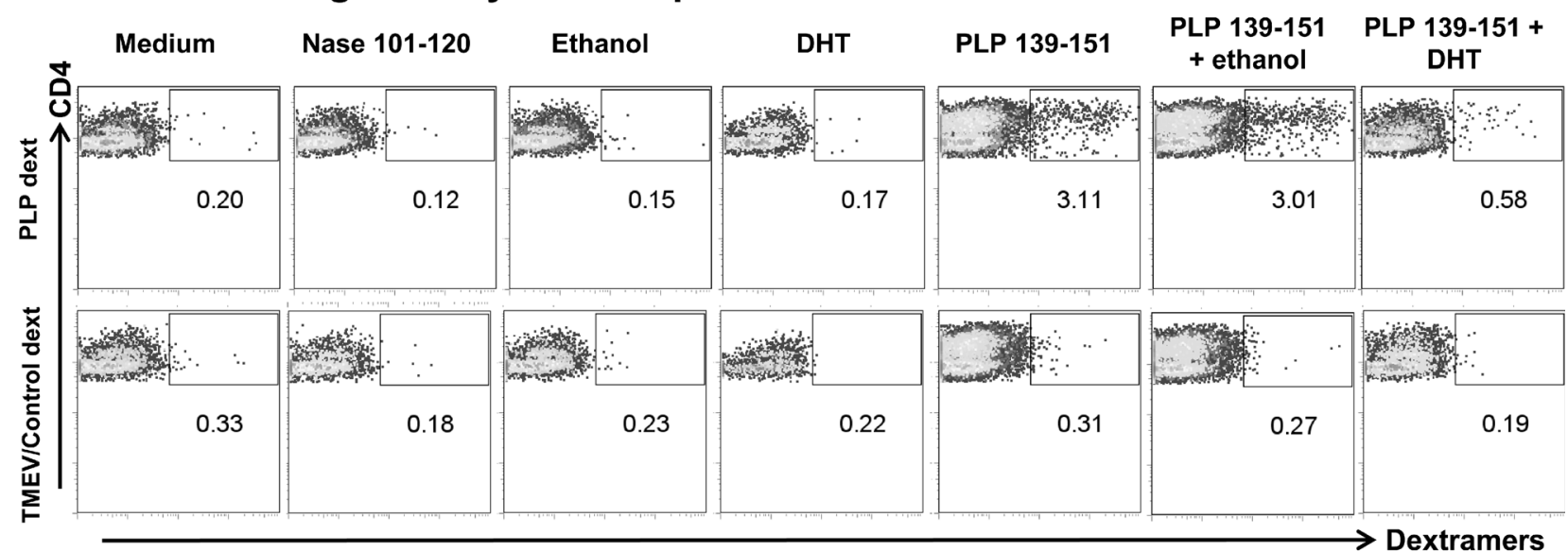

(b) Dextramer staining analysis

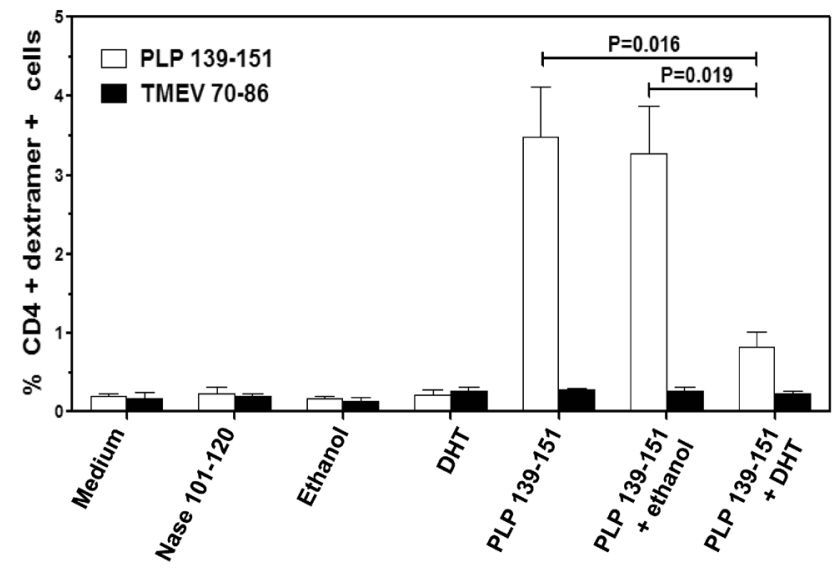

(c) Cell viability

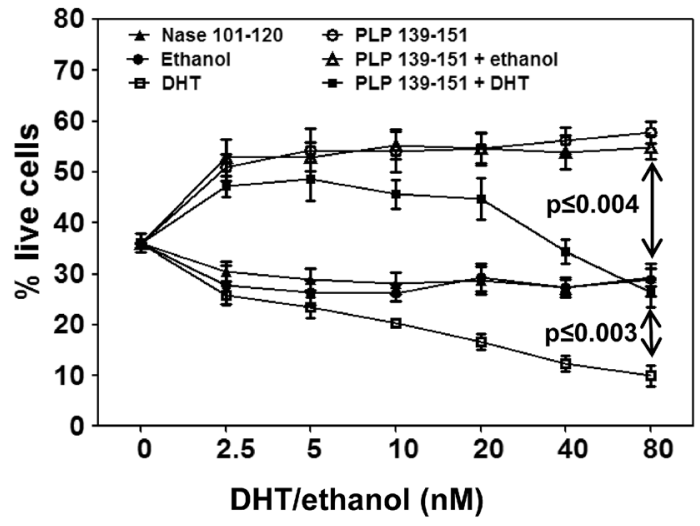

